\title{
Carcinoma de Pele no Segmento Craniofacial: Relato de três casos
}

\section{Skin Carcinoma in craniofacial segment: Report of three cases}

Joaquim José de Lima Silva ${ }^{1}$, Hafiza Gonçalves Alexandrino Regino², Iana Lara Pereira Maia², Khadija Neide Alexandrino Regino $^{3}$, Liana Barbosa e Silva2, Sônia Araújo Rogério Nunes²

1. Doutorando em Cirurgia pela Universidade Federal do Ceará, Fortaleza, Brasil e Professor do Centro Universitário Christus, Fortaleza, Brasil. 2. Estudante de Medicina pelo Centro Universitário Christus, Fortaleza, Brasil. 3. Estudante de Medicina pela Universidade Federal do Ceará, Fortaleza, Brasil.

\section{Resumo}

0 câncer de pele é a neoplasia mais frequente no Brasil. 0 tipo histológico mais comum é o carcinoma basocelular (CBC), 70\% dos casos, seguido pelo carcinoma espinocelular (CEC) e pelo melanoma. Relatamos três carcinomas de pele no segmento crânio facial, evidenciando as abordagens cirúrgicas realizadas. No caso 1, apresenta-se um CBC em hemiface submetido à exérese com retalho V-Y. No caso 2, destaca-se um CEC em couro cabeludo submetido à exérese com retalhos de rotação e da vizinhança. No caso 3, relata-se um CBC na região pré-auricular e no dorso nasal submetido à exérese com retalho de Limberg e de Rieger.

Palavras-chave: Carcinoma basocelular. Carcinoma espinocelular. Melanoma. Neoplasias cutâneas.

\begin{abstract}
Skin cancer is the most frequent neoplasia in Brazil. The most common histological type is the basal cell carcinoma (BCC), 70\% of cases, followed by squamous cell carcinoma (SCC) and melanoma. Three skin carcinomas in craniofacial segment, are repoted showing surgical approaches performed. In case 1, a BCC in hemifacial underwent excision with VY flap is presented. In case 2, we report an ECC scalp underwent excision with rotation flaps and neighborhood is reported. In case 3, report a CBC in pre-auricular region and the nasal dorsum underwent excision with Limberg flap and Rieger.
\end{abstract}

Key words: Carcinoma, Basal Cell. Carcinoma, Squamous Cell. Cancer of Skin. Melanoma. Skin Neoplasms.

\section{INTRODUÇÃO}

O câncer de pele é o mais comum no Brasil, sendo a neoplasia maligna mais frequente entre os caucasianos. Sua localização em regiões da face pode levar a sérias deformidades. O tipo mais comum de tumor maligno da pele é o carcinoma basocelular (CBC), responsável por $70 \%$ desses casos, seguido pelo carcinoma espinocelular e pelo melanoma. Cerca de $80 \%$ dos CBC são da região de cabeça e pescoço, em especial, da face ${ }^{1}$.

Os CBCs são tumores da camada basal do epitélio, presentes quase exclusivamente em locais em que há presença de pelos e são mais frequentes em regiões expostas ao sol. A exposição à radiação ultravioleta solar é o principal fator de risco isolado ${ }^{1-5}$ e é o menos agressivo dos tumores malignos da pele, apresentando raramente metástase.

Os CECS são derivados dos queratinócitos suprabasais (camada espinhosa), possui maior caráter invasivo com possibilidade aumentada de metástase.

O artigo se propõe a relatar três casos de carcinoma de pele no segmento crânio facial, evidenciando a sua abordagem cirúrgica. Os três pacientes envolvidos autorizaram formalmente a publicação dos dados e das imagens utilizadas por meio da assinatura do termo de consentimento.

\section{RELATOS DOS CASOS}

\section{Caso 1}

A.M.N, 51 anos, sexo masculino, branco. O paciente referia lesão cutânea na hemiface direita desde o nascimento, evoluindo com aumento significativo há cerca de um ano. Ao exame físico, apresentava lesão vegetante, de coloração escura, bem delimitada, na hemiface direita. $O$ paciente foi submetido à exérese da lesão, mais confecção de retalho cutâneo em V-Y. O exame anatomopatológico evidenciou Carcinoma Basocelular com margens livres.

Figura 1. CBC em hemiface direita

Figura 2. Exérese da lesão

Figura 3. Pós-operatório imediato (Retalho em V-Y)

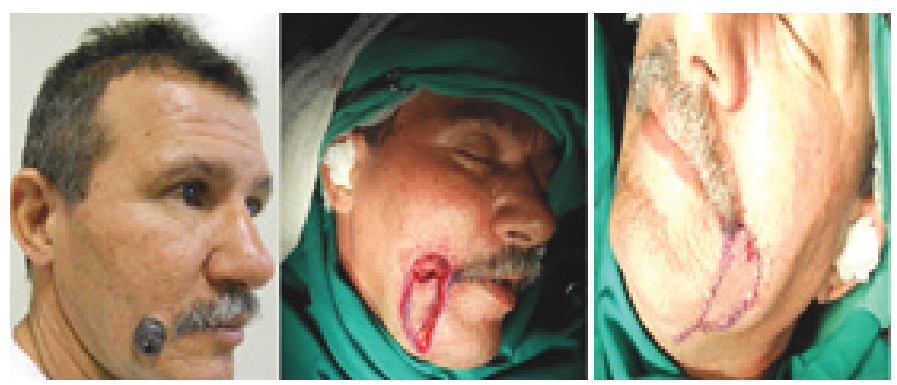

Figura 1

Figura 2

Figura 3

Correspondência: Iana Lara Pereira Maia. Estudante de Medicina do Centro Universitário Christus. Rua João Adolfo Gurgel, 133 (Campus Parque Ecológico), Fortaleza, Ceará, Brasil. E-mail: iana_lara19@hotmail.com

Conflito de interesse: Os autores declaram não ter conflito de interesses

Recebido em: 12 Mar 2014; Revisado em: 22 Abr 2014; Aceito em: 21 Jul 2014. 


\section{Caso 2}

T.S, 74 anos, sexo masculino, branco. Paciente referia lesões em couro cabeludo há cerca de 6 meses. Ao exame físico, o paciente apresentava duas lesões vegetantes ulceradas, no couro cabeludo. Foi realizado Raio $x$ de tórax no qual não foi evidenciada nenhuma alteração. Ausência de linfonodomegalias A TC de crânio apresentava-se sem alterações evidentes. Foi submetido à exérese da lesão, com confecção de 03 três retalhos de rotação, da vizinhança e fechamento primário de suas áreas doadoras. O exame anatomopatológico evidenciou Carcinoma Espinocelular com margens livres.

Figura 4. CEC em couro cabeludo

Figura 5. Exérese das lesões

Figura 6. Pós-cirúrgico imediato

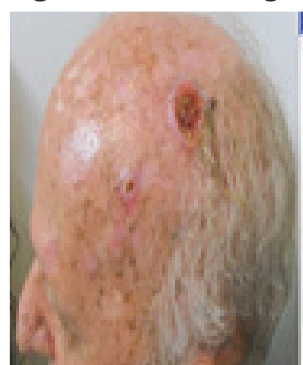

Figura 4

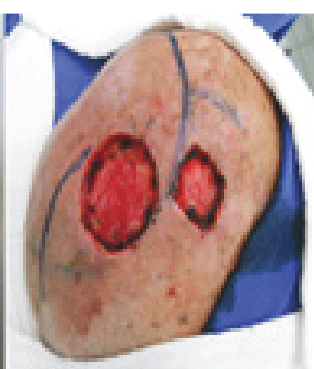

Figura 5

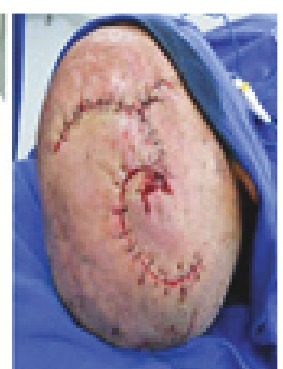

Figura 6
Caso 3

J.S.S, 76 anos, sexo masculino, cor parda. Ao exame físico, apresentava lesões vegetantes, ulceradas, localizada na região pré-auricular esquerda e no dorso nasal. $O$ paciente foi submetido à exérese das lesões com retalho de Limberg, na região pré-auricular, e retalho de Rieger no dorso nasal. 0 exame anatomopatológico evidenciou Carcinoma Basocelular com margens livres

Figura 7. CBC em região pré-auricular esquerda

Figura 8. $C B C$ em dorso nasal

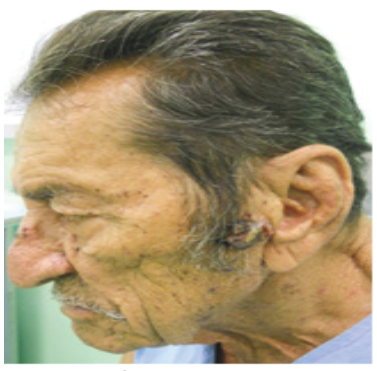

Figura 7

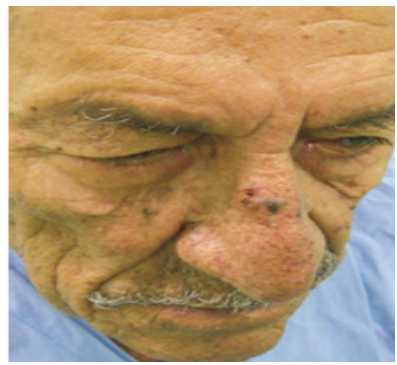

Figura 8
Figura 09. Exérese da lesão

Figura 10. Pós-cirúrgico imediato (Retalho de Limberg)

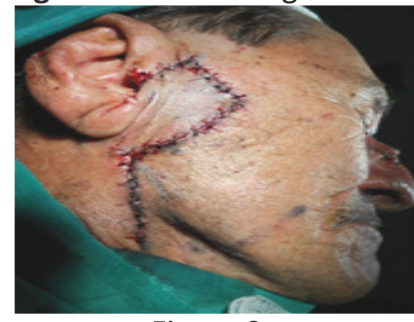

Figura 9

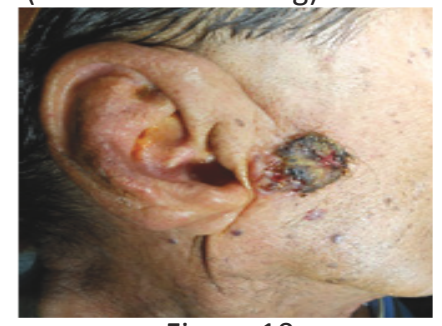

Figura 10

\section{DISCUSSÃO}

O câncer de pele pode se manifestar na forma não melanoma ou melanoma. No primeiro caso, pode apresentar tumores de linhagens distintas, como o carcinoma basocelular e o carcinoma espinocelular responsáveis, respectivamente, por cerca de $70 \%$ e $25 \%$ dos casos de câncer de pele, sendo esses os de melhor prognóstico. Já o melanoma, tipo mais agressivo, possui elevada mortalidade e baixa incidência, correspondendo a $4 \%$ dos $\operatorname{casos}^{5}$.

Podem surgir em qualquer idade, mas é a partir dos 60 anos que atingem o maior número de pessoas. Segundo o INCA (Instituto Nacional de Câncer), em 2012, a estimativa de novos casos foi de 134.170 , sendo 62.680 homens e 71.490 mulheres. Estimase um risco de acometimento por carcinomas de pele de 28 a $33 \%$ para o $\mathrm{CBC}$ e de 7 a $11 \%$ para o CEC $^{2}$.

Fatores de risco como pele clara, olhos e cabelos claros, propensão a queimaduras e a sensibilidade solar têm sido associados a maior risco para desenvolvimento do CA de pele não melanoma (CPNM). Outros fatores também já estudados foram: idade, tempo de exposição ao sol, atividade rural e histórico familiar. O consumo de álcool e o fumo, no caso do CEC do lábio, genodermatoses (xeroderma pigmentoso, síndrome do nevo basocelular), imunossupressão crônica, exposição ao arsênico, radiações ionizantes e processos dermatológicos irritativos crônicos também são outros fatores que, apesar de menos comuns, aumentam o risco para CPNM ${ }^{1}$. A susceptibilidade genética e a senilidade são outros fatores de risco bem conhecidos uma vez que os idosos têm um sistema imune menos eficiente e têm uma capacidade de reparação do DNA diminuída o que aumenta o risco de desenvolvimento da neoplasia.

Em relação ao $\mathrm{CBC}$, ele incide mais frequentemente no sexo masculino, na proporção de 3:2. É raro na raça negra e amarela e, em geral, ocorre a partir da quarta década de vida, sendo diretamente relacionado à exposição solar repetida 4,5 .

No caso 1, o paciente apresentou CBC na hemiface direita, e, no caso 3, relatou-se um paciente com $\mathrm{CBC}$ na região pré-auricular esquerda e no dorso nasal, segundo o estudo prospectivo de Ocanha (2011) . O CBC localiza-se preferencialmente nos dois terços superiores da face, acima de uma linha que vai das comissuras labiais aos lóbulos auriculares, sendo o nariz o local mais acometido, correspondendo ao percentual que varia de 25 a $30 \%$ dos casos. Em relação às subunidades nasais acometidas, tiveram uma maior incidência na ponta $(32,1 \%)$, seguidos do dorso $(22 \%)$, asa $(21,1 \%)$, parede lateral $(18,3 \%)$ e canto interno (6\%). Para reconstruções do dorso nasal, a ressecção em fuso com fechamento primário foi a mais utilizada $(62,5 \%)$, seguidos dos retalhos de dorso (16,7\%) de avanço e rotação. Enquanto o retalho utilizado em nosso caso 3, foi o de Rieger. E o caso 1, o retalho em $\mathrm{V}-\mathrm{Y}$. Na face, afeta preferencialmente a pirâmide nasal e as regiões genianas, seguindo-se as pálpebras inferiores, a fronte, as regiões temporais e os pavilhões auriculares.

Devido às características anatomopatológicas, pode ser 
classificado nos seguintes tipos: sólido, cístico, adenoide, invasivo (infiltrativo), metatípico e esclerosante (esclerodermiforme) ${ }^{1-2}$.

Os CBC nodulares são os mais comuns, responsáveis por $60 \%$ do total ${ }^{2}$. Trata-se de lesão sobrelevada, rósea, que apresenta telangiectasias nas bordas e são normalmente bem definidas. A presença de ulceração no topo do $\mathrm{CBC}$ define o tipo ulcerado. Quando existe uma disseminação superficial do $C B C$, tipo patogenoide, não nodular, é chamado de superficial. O CBC metatípico é um tipo histológico mais agressivo, que reúne características de $C B C$ e de carcinoma espinocelular, com invasividade local pronunciada. Os CBC do tipo esclerodermiforme apresentam elevadas taxas de recidiva e diagnóstico difícil. Clinicamente, aparecem como uma placa branco-amarelada, escleroatrófica, de aspecto duro, liso, sem definição clara de bordas, podendo apresentar telangiectasias, lembrando esclerodermia. A evolução é lenta e a ulceração é rara. Esse aspecto é devido a uma proliferação excessiva de estroma fibroso. Cerca de $2 \%$ dos CBC são esclerodermiformes $2,4,5$. Essa parcela é mais elevada quando se trata de casuística de serviços que são referência para casos complicados.

Como é comum nos diagnósticos de câncer, a doença é silenciosa. Os sinais não são alarmantes, mas podem ser percebidos se houver atenção. O primeiro indício da doença costuma ser uma elevação brilhante, com coloração que pode variar entre translúcida, avermelhada, castanha ou multicolorida na pele. A ocorrência de pintas, pretas ou castanhas, de formato e bordas irregulares também é um sinal, assim como o surgimento de manchas ou feridas que, além de crescer continuamente, provocam coceira, irritação, ulceras ou sangramentos.

A biópsia é o melhor método para o diagnóstico de $\mathrm{CBC}$, é bem indicada para tumores maiores, enquanto a biópsia excecional é o tratamento de escolha para as lesões menores.

As recidivas do carcinoma basocelular são problemas no acompanhamento dos pacientes. A segunda lesão ocorre em uma área até um centímetro da lesão primária, o que reflete a dificuldade de se diferenciar de uma nova lesão na vizinhança fotoexposta ${ }^{4}$.

As taxas de recorrência de $C B C$ evidênciam risco cumulativo. Quanto mais lesões uma pessoa teve, maior a probabilidade de um novo tumor. Esses dados reiteram a importância do acompanhamento oncológico, bem como a educação em saúde, promovendo medidas de fotoproteção e autoexame ${ }^{4}$.

Outro fator importante é que a metástase em carcinoma de células basais é rara, e a incidência varia em torno de 0,002 a $0,1 \%{ }^{4}$.

Os cânceres espinocelulares da pele ocupam o segundo lugar na incidência dos tumores malignos da pele, aparecendo em todas as estatísticas como responsáveis por cerca de $20 \%$ de seu total. Esse é o tumor mais comum em pacientes mais velhos. A idade média dos pacientes é de 60 anos, e 95\% dos casos ocorrem após os 45 anos de idade. É mais frequente no homem e chega a afetá-los até duas vezes mais do que as mulheres ${ }^{3}$.

O risco do desenvolvimento do câncer espinocelular é maior em brancos, com dificuldades para bronzear, tendência a queimaduras solares, cabelos claros e olhos azuis. Os cânceres espinocelulares da pele e semimucosa do lábio são devidos à radiação solar cumulativa, sendo a radiação ultravioleta o mais importante fator de risco. Tem-se a ressaltar que os cânceres espinocelulares da pele tendem a desenvolver-se em áreas previamente inflamadas ou com cicatrizes ${ }^{3}$.

O carcinoma de células escamosas (CEC) representa 90\% dos carcinomas de boca, ocorrendo com maior frequência na língua, preferencialmente na borda posterior. Os principais fatores de risco para CEC de boca são o álcool e o tabaco. A característica clássica da lesão é constituída por úlceras persistentes com endurecimento e infiltração periférica, podendo ou não estar associada a vegetações, manchas avermelhadas ou esbranquiçadas ${ }^{6}$.

No caso 2, foi relatado CEC em couro cabeludo em dois locais distintos. Segundo o estudo de Souza (2012), em uma amostra composta de 25 pacientes com CA de pele em couro cabeludo, o diagnóstico de maior incidência foi o de CEC (84\%), e a localização mais atingida foi a região biparietal (20\%).

Essa neoplasia é agressiva e normalmente espalha-se através de invasão direta e pelos canais linfáticos ${ }^{8,9}$. Na literatura, encontramos índices de $8 \%$ para recidiva local e de $5 \%$ para metástases em cinco anos. Cerca de $85 \%$ das metástases ocorre em linfonodos regionais e apenas 15\% envolvem outros órgãos, dos quais os mais frequentes são pulmão, fígado, cérebro e ossos 7 . A taxa de cura é de $95 \%$, aproximando-se de $99 \%$ quando as margens histopatológicas são negativas ${ }^{7,8,9}$.

Os cânceres de pele, especialmente quando ocorrem na face, são deformantes e mutilantes na maioria dos casos. A escolha da técnica cirúrgica é crucial para reverter elou amenizar as avarias.

\section{REFERÊNCIAS}

1-Santos ABO, Loureiro V, Araujo Filho VJF, Ferraz AR. Estudo epidemiológico de 230 casos de carcinoma basocelular agressivos em cabeça e pescoço. Rev Bras Cir Cabeça Pescoço 2007 out-dez; 36(4):230 -233.

2-Lara JRL, Miguel VER, Kowalski LP, Bottura L. Carcinoma basocelular metastático: relato de caso. An bras Dermatol 2001; 76(4):429-435.

3-Nasser N. Epidemiologia dos cânceres espinocelulares -Blumenau (SC) -
Brasil, de 1980 a 1999. An bras Dermatol 2004; 79(6):669-677.

4-Ocanha JP, Miot HA, Marques MEA, Dias JT, Stolf HO, Abbade LPF . Recidivas e recorrências de carcinomas basocelulares da face. An Bras Dermatol 2011;86(2):386-8.

5-Ferreira FR, Nascimento LFC, Rotta O. Fatores de risco para câncer da pele não melanoma em Taubaté, SP: um estudo caso-controle. Rev Assoc Med Bras 2011jul-ago; 57(4):431-437. doi: http://dx.doi.org/10.1590/S010442302011000400018 
6-Sassi LM, Oliveira BV, Pedruzzi PAG, Ramo GHA, Stramandinoli RT, Gugelmin $\mathrm{G}$ et al. Carcinoma espinocelular de boca em paciente jovem: relato de caso e avaliação dos fatores de risco. Rev Sul-Bras Odontol. 2010; 7(1):105-9.

7-Scanavini Junior RC, Martins AS, Tincani AJ, Altemani A. Fatores prognósticos do carcinoma espinocelular cutâneo de cabeça e pescoço. Rev bras cir cabeça pescoço 2007 out-dez; 36(4):226 -229.
8-Souza CD. Reconstrução de grandes defeitos de couro cabeludo e fronte em oncologia: tática pessoal e experiência - análise de 25 casos. Rev Bras Cir Plást. 2012;27(2):227-37.

9-Souza RP, Moreira PTB, Paes Júnior AJO, Pacheco Neto MC, Soares AH, Rapoport A. Carcinoma espinocelular de gengiva: análise das imagens de sete casos. Radiol Bras. 2003; 36(4): 225-227.

Como citar este artigo/How to cite this article:

Silva JJL, Regino HGA, Maia ILP, Regino KNA, Silva LB, Nunes SAR. Carcinoma de pele no segmento craniofacial: relato de três casos. J Health Biol Sci. 2014 Jul-Set; 2(3):146-148. 